NASA/TM-2006-214104

\title{
A Theoretical Solid Oxide Fuel Cell Model for System Controls and Stability Design
}

George Kopasakis

Glenn Research Center, Cleveland, Ohio

Thomas Brinson and Sydni Credle

Florida A \& M University, Tallahassee, Florida

Ming $X u$

Virginia Polytechnic and State University, Blacksburg, Virginia 


\section{NASA STI Program . . . in Profile}

Since its founding, NASA has been dedicated to the advancement of aeronautics and space science. The NASA Scientific and Technical Information (STI) program plays a key part in helping NASA maintain this important role.

The NASA STI Program operates under the auspices of the Agency Chief Information Officer. It collects, organizes, provides for archiving, and disseminates NASA's STI. The NASA STI program provides access to the NASA Aeronautics and Space Database and its public interface, the NASA Technical Reports Server, thus providing one of the largest collections of aeronautical and space science STI in the world. Results are published in both non-NASA channels and by NASA in the NASA STI Report Series, which includes the following report types:

- TECHNICAL PUBLICATION. Reports of completed research or a major significant phase of research that present the results of NASA programs and include extensive data or theoretical analysis. Includes compilations of significant scientific and technical data and information deemed to be of continuing reference value. NASA counterpart of peer-reviewed formal professional papers but has less stringent limitations on manuscript length and extent of graphic presentations.

- TECHNICAL MEMORANDUM. Scientific and technical findings that are preliminary or of specialized interest, e.g., quick release reports, working papers, and bibliographies that contain minimal annotation. Does not contain extensive analysis.

- CONTRACTOR REPORT. Scientific and technical findings by NASA-sponsored contractors and grantees.
- CONFERENCE PUBLICATION. Collected papers from scientific and technical conferences, symposia, seminars, or other meetings sponsored or cosponsored by NASA.

- SPECIAL PUBLICATION. Scientific, technical, or historical information from NASA programs, projects, and missions, often concerned with subjects having substantial public interest.

- TECHNICAL TRANSLATION. Englishlanguage translations of foreign scientific and technical material pertinent to NASA's mission.

Specialized services also include creating custom thesauri, building customized databases, organizing and publishing research results.

For more information about the NASA STI program, see the following:

- Access the NASA STI program home page at http://www.sti.nasa.gov

- E-mail your question via the Internet to help@sti.nasa.gov

- Fax your question to the NASA STI Help Desk at 301-621-0134

- Telephone the NASA STI Help Desk at 301-621-0390

- Write to:

NASA STI Help Desk

NASA Center for AeroSpace Information 7121 Standard Drive Hanover, MD 21076-1320 


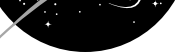

\section{A Theoretical Solid Oxide Fuel Cell Model for System Controls and Stability Design}

George Kopasakis

Glenn Research Center, Cleveland, Ohio

Thomas Brinson and Sydni Credle

Florida A \& M University, Tallahassee, Florida

Ming $X u$

Virginia Polytechnic and State University, Blacksburg, Virginia

Prepared for the

Turbo Expo 2006

sponsored by the American Society of Mechanical Engineers

Barelona, Spain, May 8-11, 2006

National Aeronautics and

Space Administration

Glenn Research Center

Cleveland, Ohio 44135 


\section{Acknowledgments}

The authors would like to thank Robert Green from NASA Glenn Research Center and Tom Hartley and Jennifer Suder from the University of Akron for the many fruitful discussions concerning fuel cell modeling.

Trade names and trademarks are used in this report for identification only. Their usage does not constitute an official endorsement, either expressed or implied, by the National Aeronautics and Space Administration.

Level of Review: This material has been technically reviewed by technical management.

Available from

NASA Center for Aerospace Information 7121 Standard Drive

Hanover, MD 21076-1320
National Technical Information Service 5285 Port Royal Road Springfield, VA 22161 


\title{
A THEORETICAL SOLID OXIDE FUEL CELL MODEL FOR SYSTEM CONTROLS AND STABILITY DESIGN
}

\author{
George Kopasakis \\ National Aeronautics and Space Administration \\ Glenn Research Center \\ Cleveland, Ohio 44135 \\ Thomas Brinson and Sydni Credle \\ Florida A \& M University \\ Tallahassee, Florida 32307 \\ Ming Xu \\ Virginia Polytechnic and State University \\ Blacksburg, Virginia 24061
}

\begin{abstract}
As the aviation industry moves towards higher efficiency electrical power generation, all electric aircraft, or zero emissions and more quiet aircraft, fuel cells are sought as the technology that can deliver on these high expectations. The Hybrid Solid Oxide Fuel Cell system combines the fuel cell with a microturbine to obtain up to $70 \%$ cycle efficiency, and then distributes the electrical power to the loads via a power distribution system. The challenge is to understand the dynamics of this complex multi-discipline system, and design distributed controls that take the system through its operating conditions in a stable and safe manner while maintaining the system performance. This particular system is a power generation and distribution system and the fuel cell and microturbine model fidelity should be compatible with the dynamics of the power distribution system in order to allow proper stability and distributed controls design. A novel modeling approach is proposed for the fuel cell that will allow the fuel cell and the power system to be integrated and designed for stability, distributed controls, and other interface specifications. This investigation shows that for the fuel cell, the voltage characteristic should be modeled, but in addition, conservation equation dynamics, ion diffusion, charge transfer kinetics, and the electron flow inherent impedance should also be included.
\end{abstract}

\section{INTRODUCTION}

Conventional electric power generation based on coal and hydrocarbon fuels causes high pollution and generates power with relative low efficiency. In aviation and in other remote power applications, like in the auto industry, weight and volume also become important design considerations. The emerging fuel cell technology offers a promising solution for powering future aircraft with reduced emissions, higher efficiencies, and with lower weights and volumes. Especially, the emissions from the fuel cells are known to be the lowest for all of the fossil fuels (refs. 1 and 2).
The hybrid Solid Oxide Fuel Cell (SOFC) power system, which is one of the top contenders for future aircraft power, incorporates a microturbine Gas Turbine Engine (GTE), a Fuel Cell (FC), and power processing and distribution hardware, shown in figure 1. The purpose for the GTE is to improve the overall system efficiency by utilizing the hot air flowing out from the SOFC and expanding it in the turbine to generate additional electrical power (refs. 1 and 2). The FC and the GTE are tightly coupled through auxiliary components such as heaters, pumps, the recuperator, heat exchangers, valves, the reformer, humidifiers, and diffusers. In this system, the fuel cell, together with the heat exchanger, effectively replaces the combustor section in a typical gas turbine engine as shown in figure 2. The GTE and the FC both generate electrical energy, which is delivered to electrical loads by an electrical power processing and distribution system. The inclusion of the GTE in the hybrid SOFC power system improves the overall efficiency by approximately $20 \%$. In a typical hybrid SOFC system, the FC will supply approximately $80 \%$ of the total output power and the GTE channel will supply $20 \%$ (refs. 2 and 3 ).

The hybrid SOFC power system involves interdisciplinary engineering, and the approach to systems modeling for dynamics and controls needs to involve this type of analytical knowledge. Often in fluidic type systems like aircraft engines, the component flows can be choked. This serves to separate the source and load impedances of the upstream and downstream components, thereby, decoupling their dynamics. In electrical power systems, choking the current flow is not an option. Therefore, the source/load dynamics must be dealt with by designing stability margins for the interface impedances (ref. 4). For stability and distributed controls design, the power system dynamics of interest typically extend to 10 's of $\mathrm{KHz}$ (depending on the switching frequency of the power processors) (ref. 5). Because in this case the SOFC is the power source, where the power distribution system behaves as the electrical load (ref. 6), the source or fuel cell dynamics should also be modeled up to this frequency range. 


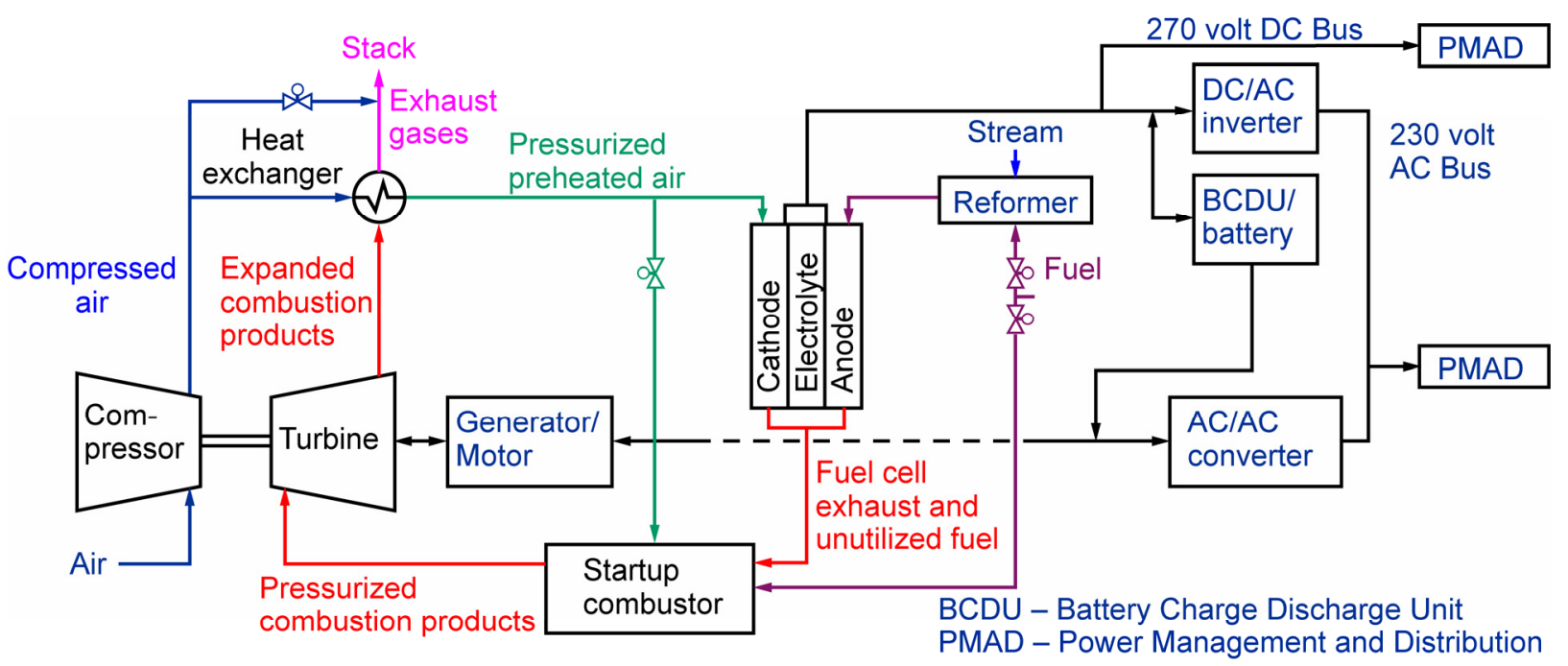

FIGURE 1.-HYBRID SOFC POWER SYSTEM STRUCTURE

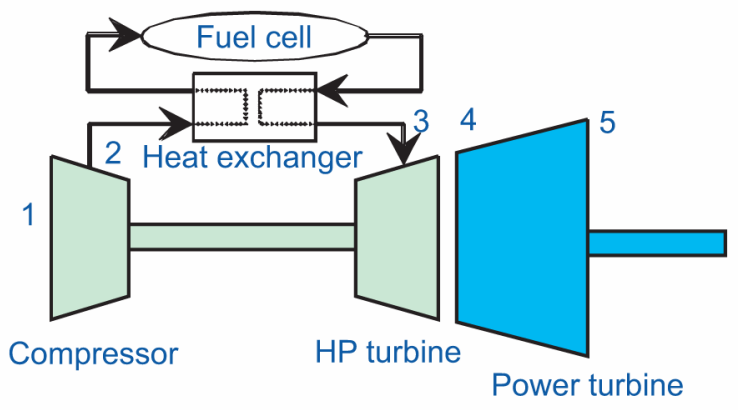

FIGURE 2.-GAS TURBINE ENGINE DIAGRAM

This frequency range (up to 10's of $\mathrm{KHz}$ ) for the SOFC also includes conservation dynamics, diffusion, kinetics, and inherent impedances. Obviously, simulating the system in this extensive frequency range that starts from sub hertz frequencies, with the temperature dynamics, can not be done effectively in the time domain. However, these models can be converted into the frequency domain, which allows the applicability of classical control and stability design approaches. Once the system is designed for distributed control and stability, more simplified models can then be used to design and assess the longer time scale system operability and performance (refs. 7 and 8). These higher fidelity models can be generated based on physics, which allows for more in depth understanding of how the process works, followed by calibration of the models based on test results. These models can also be generated strictly by testing, requiring impedance measurements in electrical systems or, equivalently, impedance spectroscopy measurements in electrochemical systems (ref. 9).

Both the GTE compressor and turbine are directly interfacing with the SOFC, see figure 1. Also, the turbine through the electrical generator interfaces with both the SOFC and the electrical power management and distribution system (ref. 10). Therefore, the GTE model fidelity (i.e., the compressor and turbine) also needs to be comparable to the rest of the system by employing the gas dynamics through the conservation equations. In some cases, the flows of the GTE and the FC maybe choked to decouple these dynamics and in such cases the models can be simplified. Work to complete the GTE portion of this model is continuing and more detailed results may be presented in the future.

This paper is organized as follows. First, details pertaining to the justification for high fidelity modeling of the SOFC for distributed controls and stability design are presented. This is followed by presenting a physics based model of the SOFC, suitable for power systems controls and stability design. Finally, concluding remarks are presented.

\section{FUEL CELL MODELING IN REMOTE ELECTRICAL POWER DISTRIBUTION SYSTEMS}

In general, (without distinction of electrical, mechanical, or electrochemical systems) when an upstream component provides energy processed or utilized by a downstream component, the two components connected together form a "source-load" configuration as shown in figure 3 for a power system (ref. 4). In this figure, $G_{S}(s)$ and $G_{L}(s)$ stand for the corresponding input to output transfer functions, $Z_{O}(s)$ and $Z_{L}(s)$ stand for the source output impedance and the load input impedance respectively, $R_{L}$ represents the load resistance, and $\mathrm{Zeq}, \mathrm{Zp}$ are the source series impedance, and the load power stage impedance respectively, which can also include filters. If these impedances are sufficiently separated as a function of frequency ( $\geq 6 \mathrm{~dB}$ or twice the magnitudes separation), then the overall transfer function formed by connecting these components can be approximated by the product of the individual component transfer functions. However, if this condition is not met, then the overall transfer function is described by the following equation:

$$
G_{T}(s)=\frac{G_{S}(s) G_{L}(s)}{1+\frac{Z_{O}(s)}{Z_{L}(s)}}
$$




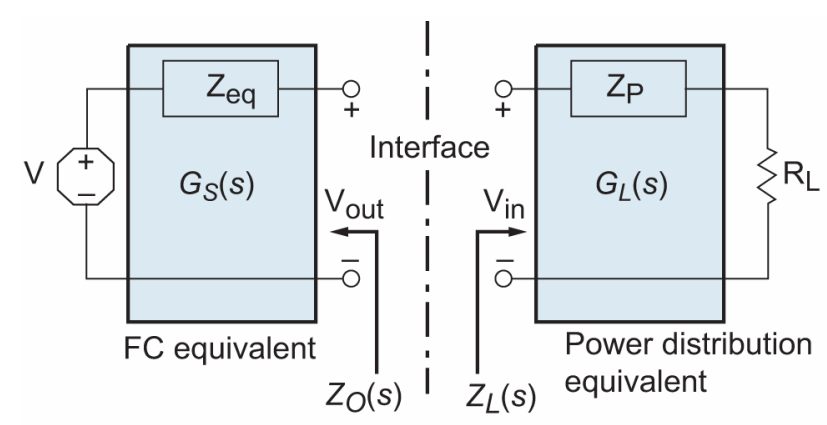

FIGURE 3.-FUEL CELL AND POWER DISTRIBUTION EQUIVALENT INTERFACE NETWORK MODEL

As seen, the denominator of equation (1) forms a characteristic equation, whose Nyquist stability criteria need to be defined and designed for. Inspection of equation (1) shows that if the magnitude of $Z_{O}(s) / Z_{L}(s)$ becomes 1 at some point in frequency, while its phase becomes $\pm 180^{\circ}$, the overall transfer function will be infinite, and thus completely unstable. There is a range of magnitudes and phases around this point where the overall transfer function of equation (1) will exhibit oscillatory behavior, which is also undesirable. The output impedance $Z_{O}(s)$ depends on the hardware designs and physics, of the fuel cell components in this case, as well as any feedback control designs.

Typical electrical power systems do not meet this condition of sufficient separation in impedances, which makes it necessary to design for adequate stability margins. Adequate stability margins are typically $60^{\circ}$ phase margin and 6 to $10 \mathrm{~dB}$ gain margin. Designing adequate stability margins is vitally important in remote power system applications, which are not afforded the stability of large interconnected networks like the terrestrial electrical power network. It is also important to design for adequate stability margins in systems with increased constant power or negative impedance loading. This is also true for remote electrical power systems where the load closely matches that of the source generating capacity, like future aircraft electrical power systems.

Figure 4 shows a generic Nyquist stability diagram for this characteristic equation, and a designated exclusion zone designed such that the interface is specified with absolute and conditional stability margins of $\geq 60^{\circ}$ phase and $6 \mathrm{~dB}$ gain. In other words, the magnitude of the $Z_{O}(s) / Z_{L}(s)$ ratio is not permitted to become greater than 0.5 while the phase of this ratio resides between 120 and $240^{\circ}$. Given the output impedance of the FC, the input impedance of the power distribution system (or the inverter in this case) interfacing the FC, will need to be designed so that the Nyquist stability criteria is satisfied. Figure 5 shows the power system stability interfaces for this simplified hybrid SOFC system diagram. Instabilities like electrical instabilities in this case (depending on their severity); can propagate through the system to also involve mechanical components, which can cause catastrophic system failures.

The following is a description of general requirements for distributed controls and stability design that pertain to interface impedances and closed loop controls design. For interface impedances, in addition to the Nyquist criterion, all frequencies should be damped. For closed loop distributed controls, the

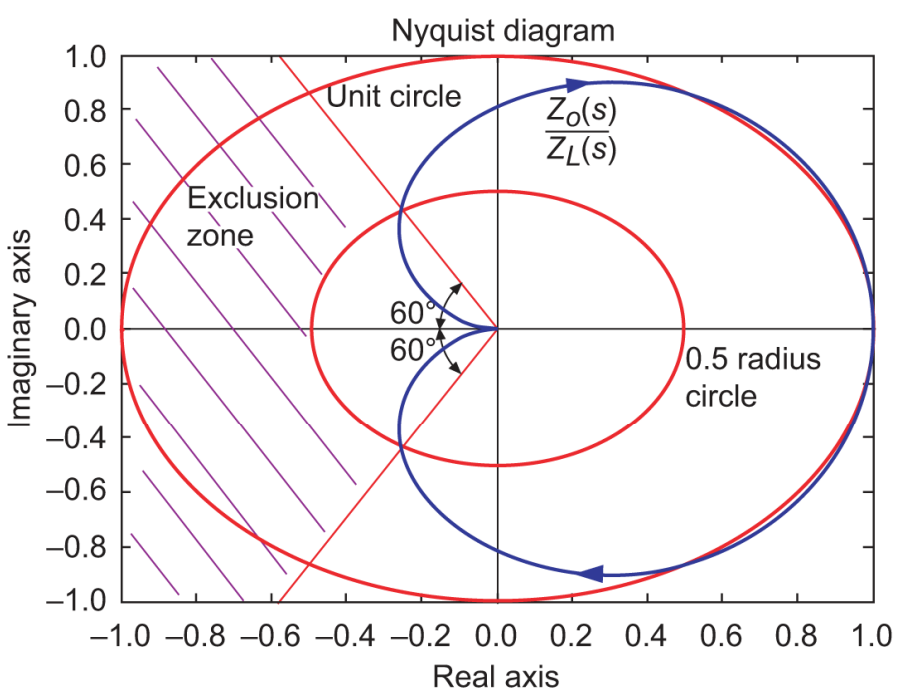

FIGURE 4.-NYQUIST STABILITY OF $Z_{O}(s) Z_{L}(s)$ FOR ABSOLUTE AND CONDITIONAL STABILITY OF $\geq 60^{\circ}$ PHASE MARGIN AND $\geq 6$ DB GAIN MARGIN

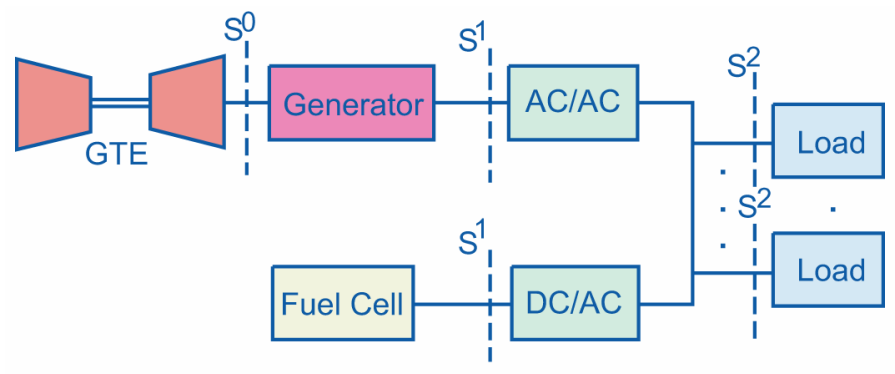

\section{FIGURE 5.-TYPICAL HYBRID SOFC POWER SYSTEM STABILITY INTERFACES (Si)}

frequencies of the various control loops should be separated when feasible, and adequate damping, phase and gain margins, and disturbance attenuation should be designed. For power stages, in addition to distributed controls, design to satisfy the Middlebrook (ref. 11) stability criterion and audio susceptibility. The design for all these specifications will necessitate developing high fidelity models of the type discussed here. For completeness, there is also stability implications associated with any device that produces thermal energy; for instance, the energy produced by the GTE and the FC could be susceptible to thermo-acoustic and the Helmholtz instabilities, but these can be addressed separately.

\section{SOFC MODELING FOR SYSTEM DYNAMIC INTERACTIONS, CONTROLS AND STABILITY}

In the previous section, the justification for the need of high fidelity dynamic modeling for the FC subsystem was covered. It was established that the FC dynamics need to extend into 10's of $\mathrm{KHz}$ to make it comparable to the dynamics of interest in a typical electrical power distribution systems for control and stability analysis. This frequency bandwidth for the FC includes the following areas for modeling: The $\mathrm{FC}$ voltage relation, conservation equations modeling for species, momentum, and energy that covers sub hertz up to 100 's of $\mathrm{Hz}$, ion diffusion that cover 100's of $\mathrm{Hz}$, charge transfer kinetics that can extend to 
10 's of $\mathrm{KHz}$, and finally the inherent impedance of the fuel cell relative to the flow of electrons.

The conservation equations govern the mass transport phenomena into the $\mathrm{FC}$ and the temperature and flow rates of the species. The gas diffusion governs the transport of ions through the porous electrode and electrolyte media to the reaction site. This reaction site is called "triple point boundary" $(t p b)$, which consists of the interface between the electrode, the electrolyte and the gasses that react. The charge transfer kinetics governs the electrochemistry reactions at the $t p b$ associated with the charge transfer and charge balance.

\section{Fuel Cell Voltage}

In the ideal gas law, the electromotive force (EMF) or reversible open circuit voltage is related to the Gibbs free energy (refs. 1 and 2) release as

$$
E=-\frac{\Delta G}{n F}
$$

where $\Delta G$ is Gibbs free energy, $F$ is Faraday's constant $[96487$ $\mathrm{C} \mathrm{mol}^{-1}$ ], and $n$ is the number of electrons participating in the reaction, which is 2 for the hydrogen/oxygen reaction. This open circuit voltage is related to the gas partial pressures and temperature through the following equation:

$$
E=E^{o}+\frac{R T}{2 F} \ln \left[\frac{p_{H_{2}}^{t}\left(p_{O_{2}}^{t}\right)^{1 / 2}}{p_{H_{2} O}^{t}}\right]
$$

where $E^{o}$ is the voltage associated with the reaction free energy, $R$ is the universal gas constant $\left[82.05 \mathrm{E}-5 \mathrm{~J} \mathrm{~mol}^{-1} \mathrm{~K}^{-1}\right.$ for pressure in atm], $T$ is the temperature, $p_{i}^{t}$ are the partial pressures of the associated gases at the $t p b$ where the reactions take place, as shown in figure 6 (ref. 18 revised). In equation (4), it is assumed that the vapor pressure of the steam at the temperature concerned $\left(p^{o} \mathrm{H}_{2} \mathrm{O}\right)$ is equal to the standard pressure $\left(p^{o}\right)$. If this is not the case, then the partial pressures of hydrogen and oxygen are divided by $p^{o}$, and the partial pressure of steam is divided by $p_{\mathrm{H} 2 \mathrm{O}}^{o}$. The actual cell voltage is reduced by irreversible losses associated with activation loss, ohmic loss, and concentration loss respectively (refs. 1 and 2) as

$$
V=E-A \ln \left(\frac{i}{i_{o}}\right)-i R_{i n}-B \ln \left(1-\frac{i}{i_{l}}\right)
$$

where $i$ is the operating current of the cell, $i_{O}$ is the exchange current, $i_{l}$ is the limiting current at which the fuel is used up at a rate equal to its maximum supply rate, $R_{i n}$ is the inherent resistance of the fuel cell, and A and B are constant coefficients determined experimentally. There is a certain I-V characteristic associated with every fuel cell, which can be constructed from experimental data, as shown in figure 7.

Equation (5) is a steady state equation that contains no source impedance dynamics. Ultimately, the objective will be to incorporate the appropriate dynamics so that this power source can be expressed as an equivalent circuit of voltage and impedance as shown in figure 3 and equation (1). Modeling the appropriate dynamics of this voltage source will allow the application of typical power system distributed controls and stability design (ref. 4).

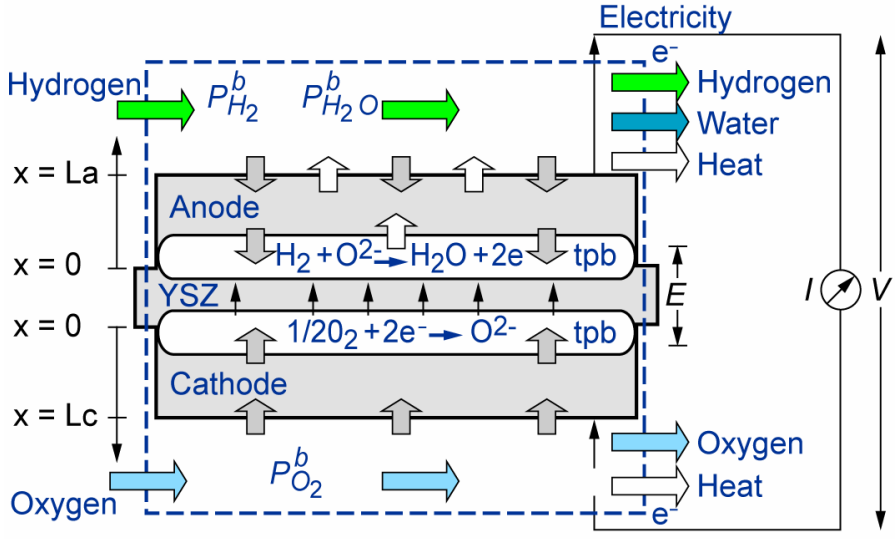

FIGURE 6.-PRINCIPLE OF THE SOLID OXIDE FUEL CELL

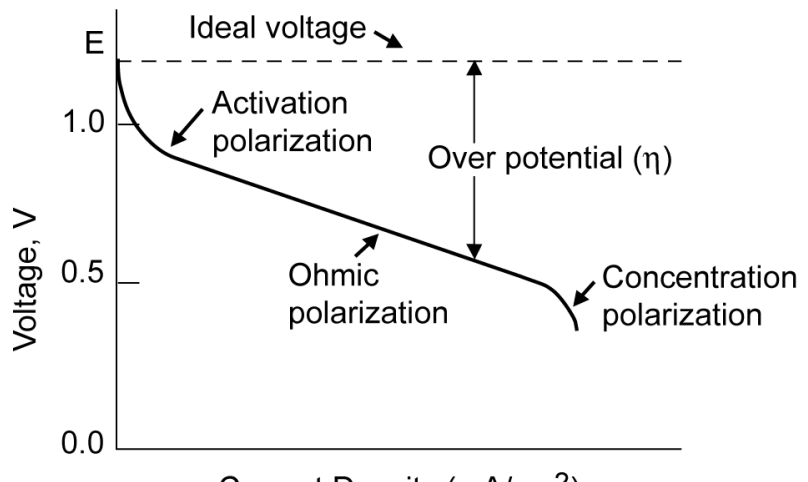

Current Density $\left(\mathrm{mA} / \mathrm{cm}^{2}\right)$

FIGURE 7.-TYPICAL FUEL CELL I-V CHARACTERISTIC

\section{Conservation Equations Modeling}

Conservation equations modeling involves mass conservation, energy conservation, and momentum conservation. These equations are expressed as one dimensional, lumped volume models. The conservation equations deal with the pressures, temperature and flows in and out of the fuel cell, shown in figure 6 . The frequencies involved in these equations start from sub hertz up to approximately $100 \mathrm{~Hz}$.

$$
\begin{gathered}
\frac{d p_{i}^{b}}{d t}=\frac{R T}{V_{c}}\left(\dot{w}_{i}^{\text {in }}-\dot{w}_{i}^{r}-\dot{w}_{i}^{\text {out }}\right) \quad \text { Mass } \\
\frac{d T}{d t}=\frac{1}{m C}\left(Q-W+\sum_{i=1}^{m} \dot{w}_{r i} \bar{h}_{r i}-\sum_{i=1}^{n} \dot{w}_{p i} \bar{h}_{p i}\right) \quad \text { Energy } \\
\frac{d \dot{w}}{d t}=-\frac{A g}{l}\left(p_{T}^{\text {in }}-p_{T}^{\text {out }}\right) \quad \text { Momentum }
\end{gathered}
$$

For the mass equation (13), $p_{i}^{b}$ is the bulk pressure due to that particular specie $i$ in the flow channel of the fuel cell. $V_{c}$ is the channel volume, and it could be different for the anode and the cathode. $\dot{w}_{i}$ is the flow rate of the specie $i$ in $\left[\mathrm{mol} \mathrm{s}^{-1}\right]$ of the incoming flow $\left(\dot{w}_{i}^{i n}\right)$, the flow that diffuses and reacts $\left(\dot{w}_{i}^{r}\right)$ and the outgoing flow $\left(\dot{w}_{i}^{\text {out }}\right)$, respectively. The reacting species 
considered with the SOFC are $\mathrm{H}_{2}, \mathrm{H}_{2} \mathrm{O}$, and $\mathrm{O}_{2}$. For the development in this subsection, ion diffusion is considered as a steady state process. Then the reactive flow in equation (6) can be represented as

$$
\dot{w}_{i}^{r}=\frac{N_{o} I}{n F}
$$

where $N_{O}$ is the number of cells in the stack in series, $I$ is the stack current, with $n=2$ for hydrogen and water and $n=4$ for oxygen (in consideration that for the same number of electrons involved $1 / 2$ mole of oxygen reacts for every mole of hydrogen), figure 6 . Later, ion diffusion will be treated for nonsteady state conditions. It could be considered that the molar flow of any gas through the valve is proportional to the partial pressure inside the channel (ref. 12) as

$$
\dot{w}_{i}=K_{i} p_{i}^{b}
$$

where $K_{i}$ is the valve molar constant for the particular specie. Equation (10) can then replace $\dot{w}_{i}{ }^{\text {out }}$ in equation (6).

For the energy equation (ref. 13), additional species could be considered of atmospheric air $\mathrm{CO}_{2}$ for the water gas shift reaction. This energy equation uses steady state cell electrochemistry calculations based on a Microsoft Excel model developed by Pacific North National Laboratory (ref. 14) (PNNL) that was converted here into MATLAB ${ }^{\circledR}$. In this PNNL model, temperature of the cell is assumed to be constant, representing the cell in a controlled temperature environment. This has been changed here, as it is not the case with a fuel cell stack, which adds heat loss to the model and a non fixed exit temperature. This change was incorporated based on equation (7), which adds temperature dynamics to the model. For the energy equation, $T$ signifies the cell or the stack temperature (i.e., the stack by dividing the equation by the number of cells in the stack). The mass is $m[\mathrm{~kg}], C$ is the specific heat capacity $\left[\mathrm{J} \mathrm{kg}^{-1} \mathrm{~K}^{-1}\right]$, which accounts for the heat capacities and the mass of the individual fuel cell materials, see table 1 for typical fuel cell materials (ref. 15). Subscript $r$ signifies the reactants while subscript $p$ signifies the products. $Q$ is the heat transfer rate $\left[\mathrm{J} \mathrm{s}^{-1}\right.$ or watts], which is the difference between the fuel cell open circuit voltage equation (3) and the operating voltage times the current in figure $7, W$ is the electrical work transfer rate [watts], and $\bar{h}$ is the total enthalpy per molar basis $\left[\mathrm{J} \mathrm{mol}^{-1}\right]$, which is the sum of the enthalpy of formations and the change in enthalpy from atmospheric conditions. It is assumed that the only heat loss is through the exit stream, because the fuel cell stack is well insulated so that the radiating heat loss is considered to be negligible.

TABLE 1.-SOFC SINGLE CELL DATA

\begin{tabular}{|l|c|c|l|}
\hline & $\begin{array}{l}\text { Spec. heat } \\
\text { cap. }\left(\mathbf{J} / \mathbf{k g}^{*} \mathrm{~K}\right)\end{array}$ & $\begin{array}{l}\text { Mass Density } \\
\left(\mathrm{kg} / \mathbf{m}^{3}\right)\end{array}$ & $\begin{array}{l}\text { Thickness } \\
(\mathrm{m})\end{array}$ \\
\hline Anode & 466 & 4200 & $\mathbf{6 \times 1 0 ^ { - 4 }}$ \\
\hline Cathode & 520 & 6350 & $5 \times 10^{-5}$ \\
\hline Electrolyte & 460 & 6010 & $1 \times 10^{-5}$ \\
\hline Interconnect & $\mathbf{8 0 0}$ & 7700 & $\mathbf{5 \times 1 0 ^ { - 4 }}$ \\
\hline
\end{tabular}
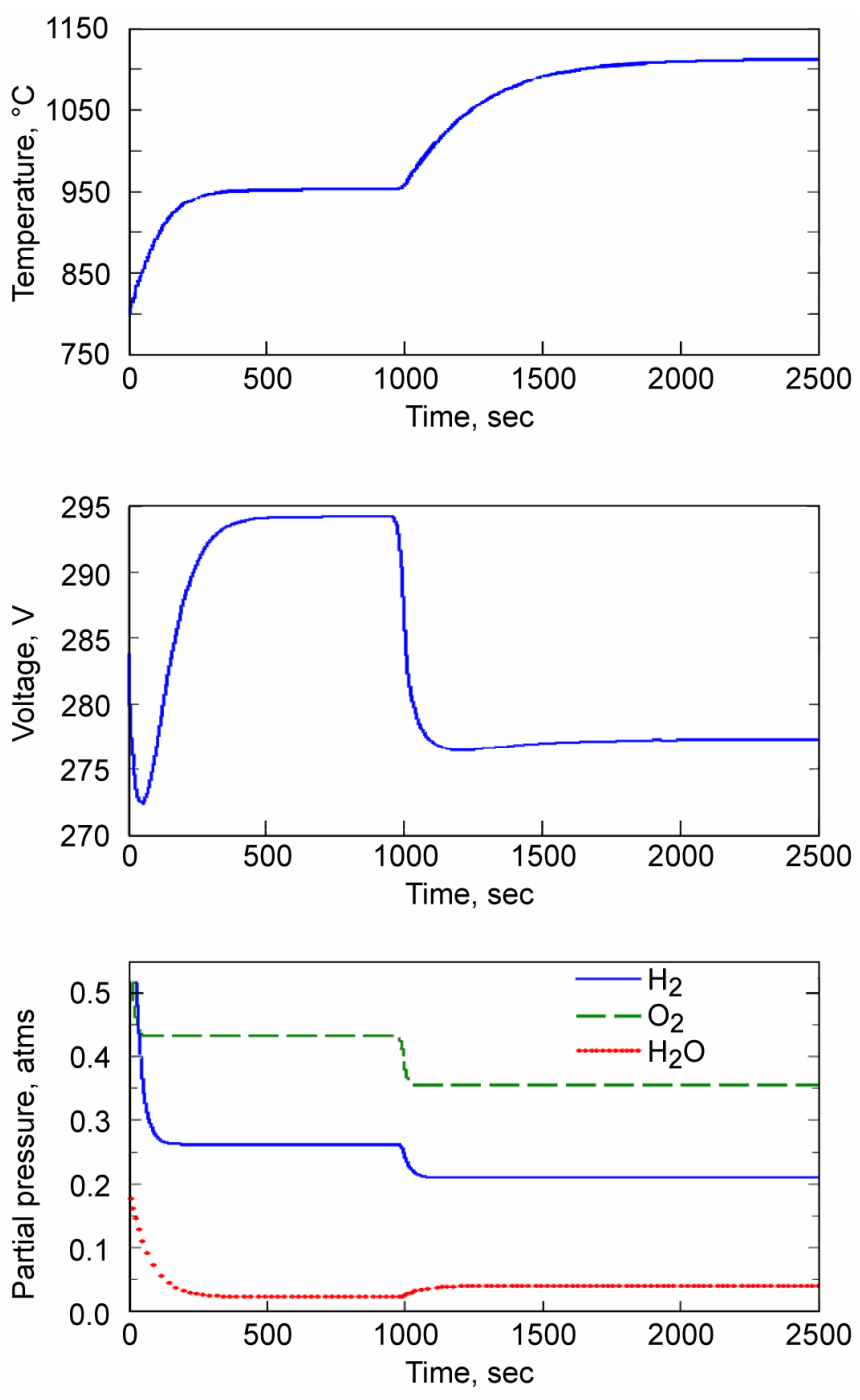

FIGURE 8.-FUEL CELL STACK SIMULATION FOR A STEP IN LOAD CURRENT (TEMP, VOLTAGE and PARTIAL PRESS)

For the momentum equation, $A$ is the flow channel cross section area $\left[\mathrm{m}^{2}\right], l$ is the length of the channel $[\mathrm{m}], g$ is the gravitational acceleration $\left[9.8 \mathrm{~m} \mathrm{~s}^{-2}\right]$, and $p_{T}$ is the total pressure [atm].

The conservation equations (6 to 8 ) tie to the voltage equation (5) by the temperature and partial pressures in equation (4). If ion diffusion is assumed to be a steady-state process, then the partial pressures at the bulk flow $p_{i}^{b}$ can be substituted for $p_{i}^{t}$ in equation (4). If ion diffusion dynamics are taken into account, as will be covered in the next subsection, then the partial pressures at the $t p b$ are computed from the bulk partial pressures in equation (6). Figure 8 shows a simulation of a fuel cell stack involving the conservation equation dynamics and the fuel cell voltage relation for a step in load current. Momentum is not simulated presently due to the specifics of stack design associated with geometric properties.

\section{Ion Diffusion Modeling}

Ion diffusion deals with the diffusion dynamics of the gas species starting from the channel flow stream entering the electrode and electrolyte porous material to the $t p b$ where the 
electrochemical reaction occurs, shown in figure 6. In equation (5), there is a voltage loss attributed to the concentration of species. In addition, there are diffusion dynamics associated with species concentration and partial pressures. These dynamics do not produce a loss per se, but rather they contribute to the voltage dynamics as a reactive impedance of the fuel cell materials to the flow of ions. The diffusion dynamics are expected to cover a frequency range extending from 100's of $\mathrm{Hz}$ up to a few $\mathrm{kHz}$.

The diffusion equation, which in this case describes the species or mass transport from the flow stream to the $t p b$ reaction site, can be written as

$$
\frac{\partial C}{\partial t}=D \frac{\partial^{2} C}{\partial x^{2}}
$$

where $C$ is the species concentration, $D$ is the effective diffusion coefficient, and $x$ is the diffusion depth as shown in figure 6 . For more detailed calculations of the diffusion coefficient based on the porosity and tortuocity of the fuel cell materials, see (refs. 16 and 17). One way to solve equation (11) is to perform a Laplace transformation to convert the partial differential equation into an ordinary differential equation (18).

$$
\frac{d^{2} C(s)}{d x^{2}}-\frac{s}{D} C(s)=0
$$

with the boundary conditions

$$
\frac{d C(s)}{d x}=-\left.\frac{1}{D} J_{o}(s)\right|_{x=0}, \quad C^{b}(s)=\left.C(s)\right|_{x=L}
$$

where $J_{o}$ is the diffusion flux $\left[\begin{array}{lll}\mathrm{mol} & \mathrm{s}^{-1} & \mathrm{~cm}^{-2}\end{array}\right]$. Solving equation (12) in terms of $C(s, x)$ results in an expression of exponential functions, which can be represented in transfer function form by applying Taylor series expansion (ref. 18). Also applying the ideal gas law, this results in the following equations:

$$
\begin{aligned}
& p_{i}^{t}(s)=G_{J P} J_{i}^{t}(s)+G_{P P} p_{i}^{b}(s) \\
& J_{i}^{b}(s)=G_{J J} J_{i}^{t}(s)+G_{P J} p_{i}^{b}(s)
\end{aligned}
$$

where

$$
\begin{gathered}
G_{J P}=K_{J P} \frac{G_{N}}{G_{D}}, \quad G_{P P}=\frac{1}{G_{D}}, \quad G_{J J}=G_{P P}, \\
G_{P J}=K_{P J} \frac{s}{G_{D}}, \quad K_{J P}=-\frac{R T L}{A D}, \quad K_{P J}=-\frac{A L}{R T} \\
G_{N}=\frac{L^{2}}{6 D} s+1, \quad G_{D}=1+\frac{L^{2}}{2 D} s+\frac{L^{4}}{24 D^{2}} s^{2}
\end{gathered}
$$

with the partial pressures $p$ at the tpb and the bulk flow represented by the superscripts $t$ and $b$ respectively. $J^{b}$ and $J^{t}$ signify the diffusing flow rate at the bulk flow boundary and the reactive flow rate at the $t p b$ respectively in $\left[\mathrm{mol} \mathrm{s} \mathrm{s}^{-1}\right]$. The diffusion cross section area is $A\left[\mathrm{~m}^{2}\right]$, and $L$ is the thickness of the diffusion layer $[\mathrm{m}]$, which can be different for the anode and the cathode. In figure 6 , it can be seen that oxygen in addition diffuses through the electrolyte layer. However, because the electrolyte layer is ionically highly conductive, its associated dynamics could be much faster, and it is assumed that these dynamics can be neglected. Inspection of the transfer functions in equation (14) shows that that their frequencies are as follows

$$
\omega_{p}=2 \sqrt{6} \frac{D}{L^{2}}, \quad \omega_{Z 1}=\frac{6 D}{L^{2}}
$$

where $\omega_{p}, \omega_{z 1}$ are the frequency of the double pole location and the zero, respectively $\left[\mathrm{rad} \mathrm{s}^{-1}\right]$. The zero of $G_{P J}$ is located at zero radians. Based on this, the diffusion response time will be proportional to the $D / L^{2}$ ratio, which means that the response is inversely proportional to the square of the diffusion layer thickness and proportional to the effective diffusion constant.

Similarly (as in the previous subsection), the assumption here is that the charge transfer kinetics is a steady state process in order to allow coupling of the diffusion process to the conservation equations. This assumption implies that as long as the reaction at the $t p b$ is not concentration limited, the reaction rate [moles $\mathrm{s}^{-1}$ ] will adjust instantaneously to meet a change in electrical current demand. Then the reactive flow at the $t p b$ can be expressed as

$$
J_{i}^{t}=\frac{N_{o} I}{n F}
$$

This relaxes the previous assumption of a steady state diffusion process, reflected in equation (9), and equation (9) now becomes

$$
\dot{w}_{i}^{r}=J_{i}^{b}
$$

which effectively ties ion diffusion to the dynamics of the conservation equations. Figure 9 shows a cell simulation of the mass flow rates of hydrogen and oxygen at the bulk flow channels and their respective partial pressures at the $t p b$, due to a step in load current at $0.05 \mathrm{~s}$. Also, figure 10 shows the same variables plotted for a step change in the bulk flow partial pressures. In these simulations, diffusion has not been tied to the conservation equations dynamics. In the more detail plots of figures 9 and 10, it can be seen that the steady-state molar flow rate of $\mathrm{H}_{2}$ is twice that of $\mathrm{O}_{2}$, which satisfies the chemical reactions of these species as shown in figure 6.

\section{Charge Transfer Kinetics Modeling}

Charge transfer kinetics, or what is also commonly referred to as charge balance, deals with the actual reactions that take place at the FC tpb's, see figure 6. This area of research is still in its relative early stages in terms of understanding the reaction mechanisms that take place at these tpb's and how to model these reactions (refs. 19 and 20). Models can also be generated or optimized by performing impedance spectroscopy testing, but testing alone would make it difficult to separate the cell dynamics due to diffusion from those due to kinetics. Also, models generated by impedance spectroscopy alone will need to be revaluated at various operating conditions, which can complicate the controls development. 

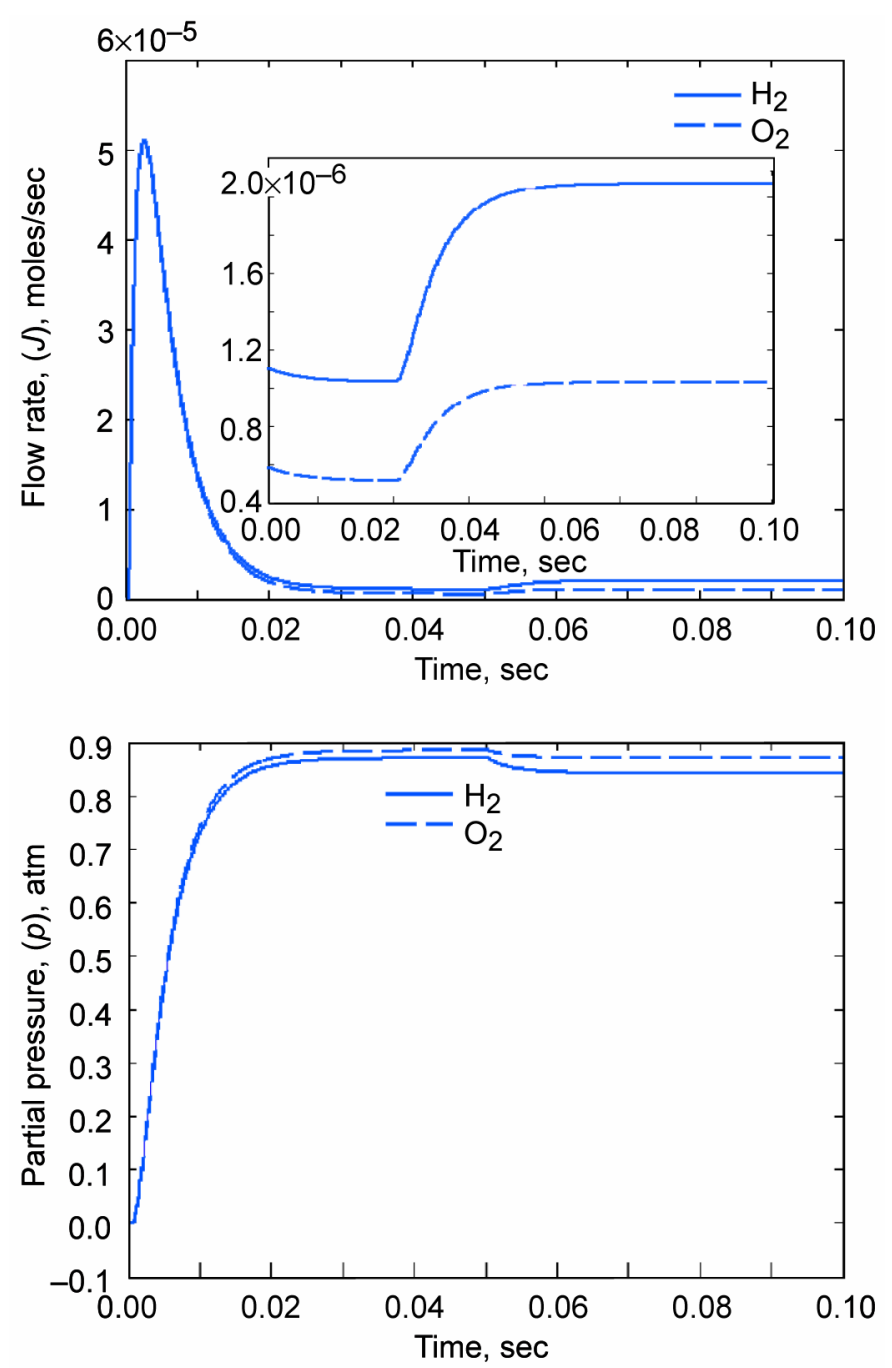

\section{FIGURE 9.-CELL SIMULATION OF MASS FLOW RATE AT THE BULK CHANNEL AND PARTIAL PRESSURES AT $t p b$ DUE TO A STEP IN LOAD CURRENT}

First some chemical background; the cell electrochemical model describes a set of possible chemical and electrochemical reactions that are derived from basic surface electrochemistry. These reactions are of the following form

$$
\begin{gathered}
a A+b B \leftarrow \frac{k_{1,} k_{-1}}{\rightarrow} c C \\
\frac{d[A]}{d t}=k_{-1} a[C]^{c}-k_{1} a[A]^{a}[B]^{b}
\end{gathered}
$$

where $A, B$, and $C$ are gas phase species, surface species absorption sites, or electrons; $k_{l}$ and $k_{-l}$ are reaction rate constants for the forward and the backward reactions, respectively. The chemical and electrochemical equations canbe formulated as mass and charge balance. The concentration or mass balance concerning the time dependant surface species $A$ is given by the corresponding differential equation in equation (17). Both the anodic and the cathode reactions need to be considered separately.
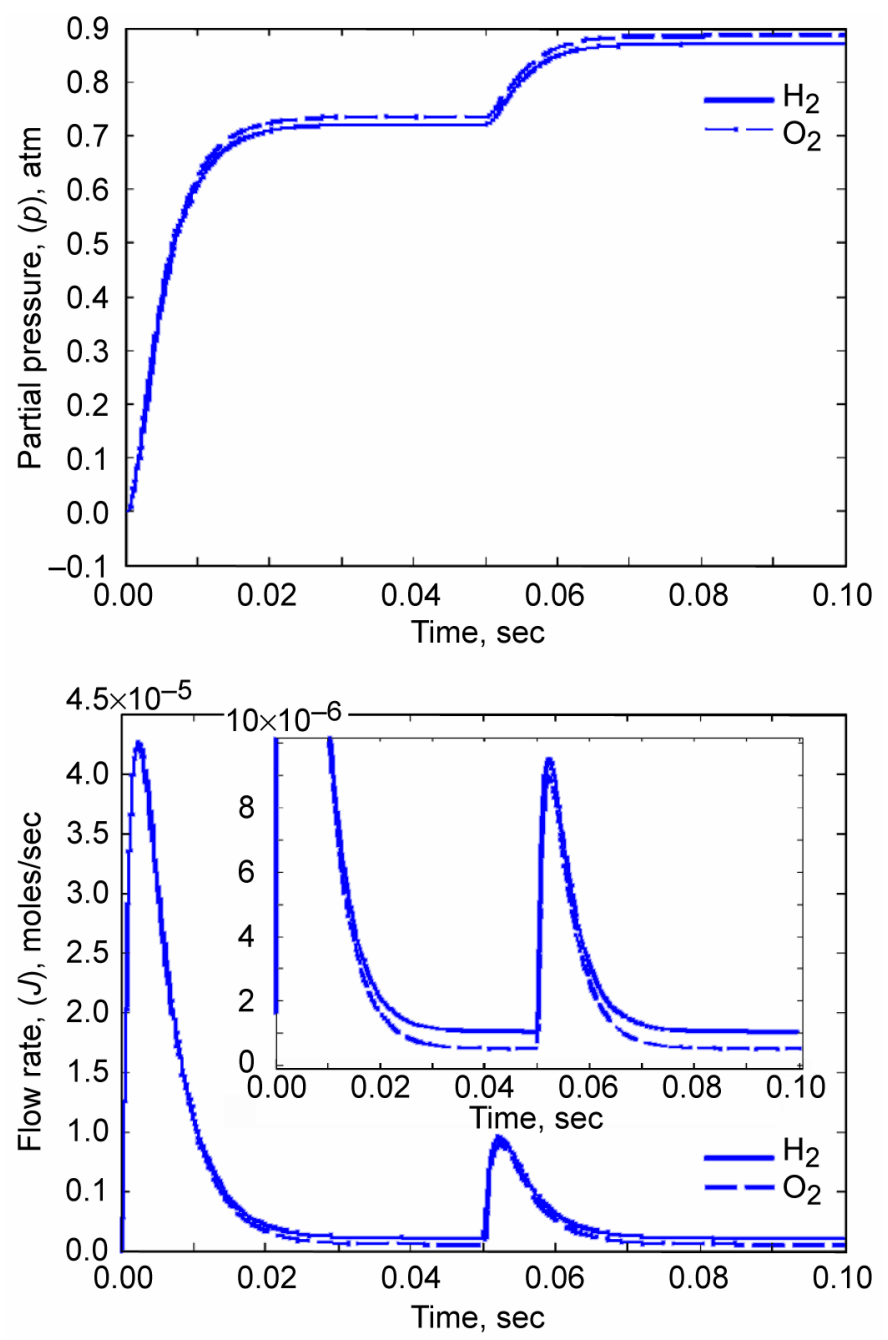

FIGURE 10-CELL SIMULATION OF MASS FLOW RATE AT THE BULK CHANNEL AND PARTIAL PRESSURES AT $t p b$ DUE TO A STEP IN PARTIAL PRESSURE AT THE BULK FLOW

Modeling of the Anodic Reactions.-The predominant electrochemical reactions (ref. 19) concerning the SOFC at the anodic $t p b$ are:

$$
H_{2(g)}+2 a d \leftarrow \frac{k_{1}, k_{-1}}{\rightarrow 2 H_{a d}}
$$

$$
\begin{gathered}
\mathrm{H}_{2} \mathrm{O}(\mathrm{g})+\mathrm{ad} \leftarrow \frac{k_{2, k_{-2}}}{\mathrm{H}_{2} \mathrm{O}} \mathrm{ad} \\
\mathrm{O}_{a d}+\mathrm{H}_{a d} \leftarrow \frac{k_{3,} k_{-3}}{\rightarrow \mathrm{HO}_{a d}+a d} \\
\mathrm{H}_{2} \mathrm{O}_{a d}+\mathrm{O}_{a d} \leftarrow \frac{k_{4}, k_{-4}}{\rightarrow} \rightarrow 2 \mathrm{OH}_{a d}
\end{gathered}
$$




$$
\begin{gathered}
H_{2} \mathrm{O}_{a d}+{ }_{a d} \leftarrow \frac{k_{5}, k_{-5}}{\mathrm{OH}_{a d}+H_{a d}} \\
\mathrm{O}_{o}^{x}+a d \leftarrow \frac{k_{6,} k_{-6}}{\rightarrow} O_{a d}+V_{o}^{\prime \prime}+2 e_{\bar{N} i}
\end{gathered}
$$

where $g$ denotes the gas phase and $a d$ denotes the absorbed phase. $k_{i}$ are the reaction rate constants for the different reaction steps, and $O^{x}$ denotes the oxygen interstitial and $V$ an oxygen vacancy. Based on that, the time dependant concentration or fraction of surface coverage $\theta_{i}$ is (ref. 19)

$$
\begin{aligned}
\frac{d \theta_{H}}{d t}= & 2 k_{1} p_{H_{2}}^{t}(1-\theta)^{2}-2 k_{-1} \theta_{H}^{2}-k_{3} \theta_{H} \theta_{O} \\
+ & k_{-3} \theta_{O H}(1-\theta)+k_{5} \theta_{H_{2} O}(1-\theta)-k_{-5} \theta_{O H} \theta_{H} \\
\frac{d \theta_{O H}}{d t}= & k_{3} \theta_{O} \theta_{H}-k_{-3} \theta_{O H}(1-\theta)+2 k_{4} \theta_{H_{2} O} \theta_{O} \\
& -2 k_{-4} \theta_{O H}^{2}+k_{5} \theta_{H_{2} O}(1-\theta)-k_{-5} \theta_{O H} \theta_{H} \\
\frac{d \theta_{H_{2} O}}{d t}= & k_{2} p_{H_{2} O}^{t}(1-\theta)-k_{-2} \theta_{H_{2} O}-k_{4} \theta_{H_{2} O} \theta_{O} \\
& +k_{-4} \theta_{O H}^{2}-k_{5} \theta_{H_{2} O}(1-\theta)+k_{-5} \theta_{O H} \theta_{H} \\
\frac{d \theta_{O}}{d t}= & -k_{3} \theta_{O} \theta_{H}+k_{-3} \theta_{O H}(1-\theta)-k_{4} \theta_{H_{2} O} \theta_{O} \\
& +k_{-4} \theta_{O H}^{2}+i_{K}
\end{aligned}
$$

Equations (19 to 22) are nonlinear and would need to be linearized by an appropriate method for frequency domain analysis. The total fraction of surface coverage, $\theta$ is $\theta=\theta_{H}+\theta_{O H}+\theta_{H 2 O}+\theta_{O}$. The reaction rate constants of $k_{l}$ and $k_{2}$ in $k_{1} p_{H_{2}}^{t}$ and $k_{2} p_{H_{2} O}^{t}$ are not constant as the partial pressures are modified. The interface reaction is

$$
O_{o}^{x}+(1-\theta) \stackrel{k_{i}, k_{-i}}{\longrightarrow} \theta_{o}+V_{o}^{\prime \prime}+2 e_{N i}
$$

Electrical current is related to the rate of electron production crossing a given cross section area per second, which is related to the molar flow rate of the reaction as

$i=\frac{d q_{e^{-}}}{d t}=\frac{1}{2} \frac{d V_{o}^{\prime \prime}}{d t}=\frac{1}{2} \frac{d \theta_{o}}{d t}=-\frac{1}{2}=\frac{d O_{o}^{x}}{d t}=-\frac{1}{2} \frac{d(1-\theta)}{d t}$

where $q$ is the electrical charge [Coulombs]. Current flows in the direction of $e^{-}$production as $i=i_{f}-i_{r}$. Applying the ButtlerVolmer equation and interface reaction gives

$i_{K}=k_{o}\left\{e^{-2(1-\beta)\left(\frac{F}{R T} \eta\right)}\left[O_{o}^{x}\right](1-\theta)-e^{-2 \beta\left(\frac{F}{R T} \eta\right)} \theta_{o}\left[V_{o}^{\prime \prime}\right]\right\}$

where $k_{O}$ is a reaction constant, $\beta$ is a charge transfer coefficient, and $\eta$ is the overpotential, see figure 7. In equations (19) and (21) the partial pressures at the $t p b$ are substituted in the place of the partial pressures at the bulk flow, used in (ref. 18). With the inclusion of the kinetics modeling of equations (19 to 22), and the calculation of the charge balance in equation (25), equation (15) in the previous section becomes

$$
J_{i}^{t}=\frac{N_{o} i_{K}}{n F}
$$

These changes essentially tie the conservation equations and ion diffusion to the charge transfer kinetics. The overpotential in equation (25) can be calculated as

$$
\eta=E_{o}-V
$$

where $E_{O}$ is the fuel cell open circuit voltage and $V$ is the actual operating voltage of the fuel cell, equation (5). The multitude of reaction rate constants makes it difficult to produce meaningful simulation results, without the benefit of optimizing the model based on test data.

For the moment, this model development assumes that the ion concentration of $O_{O}^{x}$ in the YSZ electrolyte is constant, thereby, ignoring the kinetics at the cathode $t p b$. However, similar to the development of the kinetics at the anode $t p b$, the kinetics at the cathode $t p b$ also need to be considered.

Modeling the Cathode Reactions.-The electrochemical reaction of oxygen reduction at the cathode tpb is described in (ref. 20). The overall reaction is considered to consist of several elementary reactions, mainly those associated with oxygen absorption, desorption, diffusion, and electronation. It is assumed that this process is dominated by the following reactions; (ref. 20)

$$
\begin{gathered}
O_{2(g)}+2 s \leftarrow \stackrel{k_{a d}, k_{d e s}}{-} \rightarrow 2 O_{a d} \\
O_{a d}+V_{o}^{\prime \prime}+2 e^{-} \leftarrow \stackrel{k_{1 c}, k_{-1 c}}{-} \rightarrow O_{o}^{x}+s
\end{gathered}
$$

where $s$ is the concentration of vacant surface sites, similar to (1- $\theta$ ) from before and $k_{a d}, k_{\text {des }}$ signify the oxygen absorption and desorption reaction rates. If the model is normalized by introducing $N_{O}$, the maximum number of surface sites per unit area which can be occupied by $O_{a d}$, then the time dependent concentration or fraction of surface coverage $\theta_{a d}$, (ref. 20), is

$$
\begin{gathered}
\frac{d \theta_{a d}}{d t}=2 k_{a d} p_{O_{2}} N_{O}\left(1-\theta_{a d}\right)^{2}-2 k_{d e s} N_{O} \theta_{a d}^{2} \\
-i_{C} /\left(2 N_{O} F A_{c}\right) \\
i_{c}=2 N_{O} F A_{c}\left[k_{-1 c}\left[O_{O}^{x}\right]\left(1-\theta_{a d}\right)-k_{1 c}\left[V_{o}^{\prime \prime}\right] \theta_{a d}\right]
\end{gathered}
$$

where the reaction rate constants $k_{l c}$ and $k_{-l c}$ are

$$
k_{1 c}=k_{1 c 0} e^{-2 \beta \frac{F}{R T} \eta}, \quad k_{-1 c}=k_{-1 c 0} e^{-2(1-\beta) \frac{F}{R T} \eta}
$$

and $k_{1 c 0}$ and $k_{-1 c 0}$ are potential independent reaction rates that depend on temperature. Alternatively, equation (25) can also be expressed exactly as equation (31) where it is a function of its triple point boundary area with the reaction rates of $k_{6}$ substituted for $k_{l c}$. The time dependent concentration of $O_{O}^{X}$, $\theta_{O X}$ could be expressed as 


$$
\begin{gathered}
\frac{d \theta_{o x}}{d t}=k_{1 c} \theta_{a d}-k_{-1 c} \theta_{o x} \\
O_{O}^{x}=\rho_{o x} \theta_{O x}
\end{gathered}
$$

where $\rho_{o x}$ is the maximum density of reduced oxygen per unit area $\left[\right.$ moles $\left.-\mathrm{m}^{-3}\right]$. Equations (32) and (33) are an extension of that presented in (ref. 20) and may need to be further investigated. Equation (33) can be substituted into (25) to calculate the anodic current. The anodic and the cathode currents in equations (25) and (31) will need to be balanced, which will call for an iterative procedure. The overpotential $\eta$ can be different for the anode and the cathode based on the voltage equations for their respective tpb's, and the overall voltage would be the difference of the anodic and the cathode voltages as

$$
V=V a-V c
$$

The anodic and the cathodic impedances can be computed separately based on the models presented above and the reaction rate constants (refs. 19 and 20) at some operating point by applying a sinusoidal perturbation as

$$
Z_{a, c}=\left[\frac{\partial i}{\partial \eta}\right]_{o p e r}^{-1}
$$

Figure 11 shows the cathodic impedance plot of equations (30), (31), and (35) for an operating overpotential of $0.1 \mathrm{~V}$, for certain temperature and pressure, and without combining the anodic and cathodic systems. The anodic impedance has about the same shape as the cathodic impedance. But the anodic impedance is more difficult to determine without the aid of test data due to the multitude of reaction rate constants.

The FC reactions are still an area of intensive research. The reactions presented here may not describe too accurately what happens at these tpb's. However, in the case of the anodic kinetics, which in this case is described by a fourth order model, it is expected that the order of the model is high enough to accurately model the impedance data obtained by testing.

\section{Fuel Cell Impedance}

Inherent impedance of the FC is complex, and there are many references that devote discussions in this area (refs. 9, 18, 19, and 20). Figure 12 shows an equivalent circuit of the FC impedance. In this circuit, $C_{d l a}$ and $C_{d l c}$ represent the charge double layer capacitance between the anode, cathode and the electrolyte. The anode and cathode diffusion impedances, which are not explicitly shown here, are represented by $Z_{d a}$ and $Z_{d c}$. The combination of $R_{t}, R_{p}$, and $C_{l}$ form the kinetic impedances for the anode and cathode. The charge transfer resistance is represented by $R_{t}$ and $R_{p}$ stands for the polarization resistance, and $C_{l}$ is an equivalent capacitance of the kinetic impedance. The electrolyte resistance is represented by $R_{e}$. In this circuit the resistances of the anode and the cathode electrodes together with the interconnect resistances are not shown. But if these resistances are significant compared to the rest of the impedance circuit, they can be added to the respective ends of the circuit in figure 12. For complete FC impedance for the purposes of control and stability analysis, the equivalent

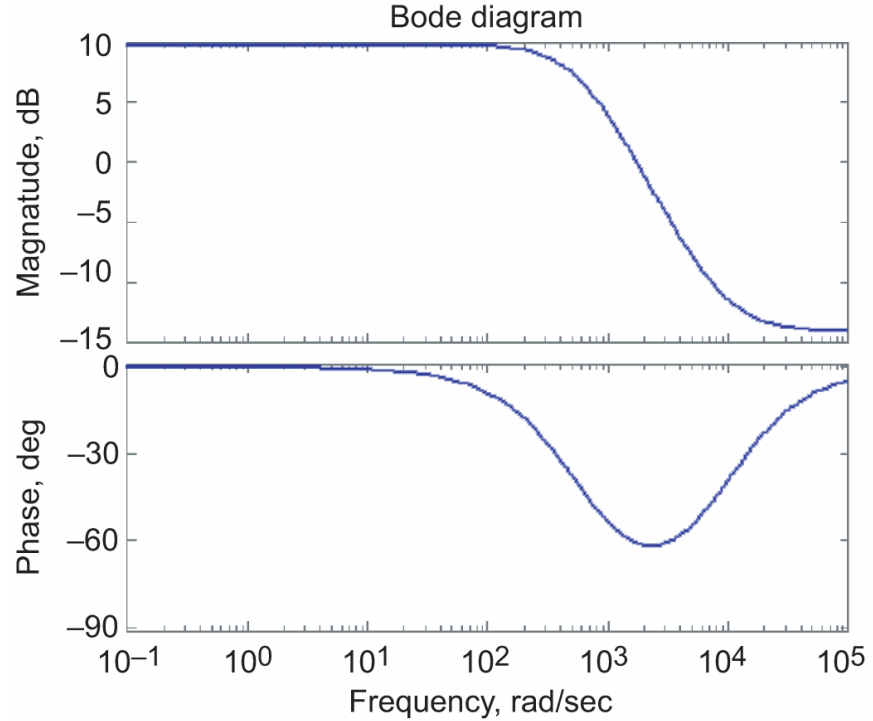

FIGURE 11.-BODE PLOT OF THE CATHODIC IMPEDANCE

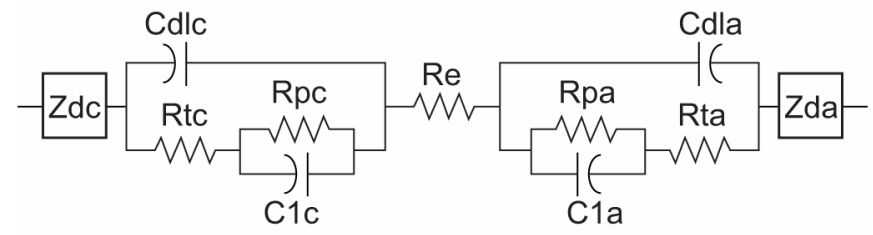

FIGURE 12.-EQUIVALENT FUEL CELL CIRCUIT

impedances due to the conservation equations (6 to 8), plus those of any feedback controls would need to be included. This work is still in progress.

These impedances can be computed by linearizing the models in MATLAB ${ }^{\circledR}$, computing the state space matrices, and then plotting the response in a Bode plot. The equivalent circuit can then be constructed based on the Bode plot. For the Bode plot of figure 11, the low frequency intercept is the resistance $R_{p c}+R_{t c}$ in the circuit of figure 12. The low frequency corner frequency is $\omega_{\mathrm{zc}}=1 /\left[\left(R_{p}+R_{t}\right) C_{l}\right]$ in radians/sec. The higher frequency intercept is equal to $R_{t c}$, and the upper corner frequency is $\omega_{\mathrm{pc}}=1 /\left(R_{t} C_{1}\right)$. Based on this $R_{p c} \sim 3 \Omega, R_{t c} \sim 0.2 \Omega$ and $C_{l c} \sim$ $5.6 \times 10^{-4} \mathrm{~F}$. As a result, the cathodic impedance would be

$$
Z_{k c}(s)=\left(R_{p c}+R_{t c}\right) \frac{\left(s / \omega_{Z c}+1\right)}{\left(s / \omega_{P c}+1\right)}
$$

The output impedance of the circuit, which is important for stability design of the fuel cell power system as was discussed earlier, can be computed by applying a sinusoidal small magnitude current sweep at the right hand side of the circuit of figure 12 and computing the voltage drop due to this excitation as shown in figure 13 as

$$
Z_{O}=\left[\frac{\partial V}{\partial I}\right]_{\text {oper }}
$$




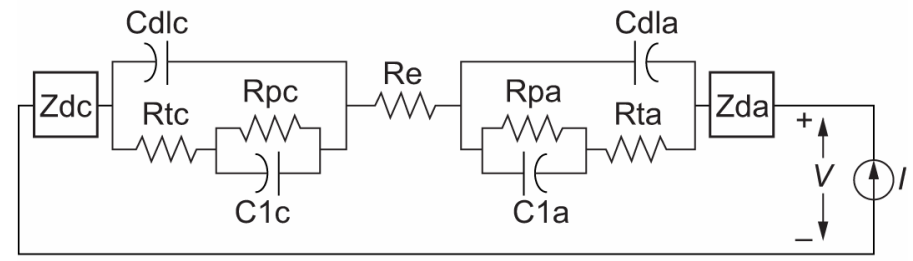

FIGURE 13.-CIRCUIT FOR COMPUTING OUTPUT IMPEDANCE

To actually compute the FC output impedance the conservation equation equivalent impedance will also need to be included, which would also depend on any regulating control loops for the fuel cell.

\section{CONCLUSION}

Modeling the Solid Oxide Fuel Cell to compute its impedance is important in the area of electrochemistry in order to understand and improve the fuel cell performance. As covered in this paper, this area of modeling is also important in order to understand how to design to interface the fuel cell with remote power systems for applications such as those found in aviation, terrestrial vehicles, and the ship power industry. For this purpose, generic models have been developed to cover the fuel cell conservation equations, ion diffusion, charge transfer kinetics, and inherent impedance modeling. So far, most of the models covered in this paper have been presented in the time domain.

To develop the fuel cell impedance for control and stability, these models will need to be incorporated in the frequency domain with equivalent circuit representations. As such, the work to develop the overall frequency domain model of the fuel cell impedance is continuing, as well as calibrating the models with actual fuel cell test data. It may turn out through testing that more than one frequency domain model is needed to cover the fuel cell operating range. Also, for a complete model of the hybrid FC power system the gas turbine model, the power distribution, and the various auxiliary component models will need to be developed. This work is still in progress in various degrees of completion.

\section{REFERENCES}

1. National Energy Technology Laboratory, "Fuel Cell Handbook 6th Edition," Morgantown, WV, 2002.

2. Larminie J.; Dicks A.; "Fuel Cell Systems Explained," John Wiley and Sons, Inc., New York, NY, 2003.

3. Schonewald R.; "Gas Turbine Technology for SOFC-GT Systems," International Colloquium in Environmentally Preferred Advance Power Generation, ICEPAG, 2004.

4. Lee F.C.; Boroyevich D.; "Modeling and Control Design of DC/DC Converters," Short Course in Power Electronics, Virginia Polytechnic and State University, Blacksburg, VA.
5. Ridley R.B.; "A new Small-Signal Model for Current-Mode Control," Proceedings of Power Conversion and Intelligent Motion Control Conference, 1989.

6. Wang C.; Lu B.; Qiu Y.; Huang B.; Xu M.; Lee F.C.; Kopasakis G.; "Control of the Hybrid Solid Oxide Fuel Cell Power System," CEPS Conference, Blacksburg, VA, 2005.

7. Huang B.; Qiu Y.; Lu B.; Wang C.; Xu M.; Lee F.C.; Kopasakis G.; "Modeling and Simulation of the Start-up Process of the Turbo Subsystem in Hybrid SOFC Power Systems," CEPS Conference, Blacksburg, VA, 2005.

8. Qiu Y.; Lu B.; Wang C.; Huang B.; Xu M.; Lee F.C.; Kopasakis G.; "Modeling and Control of Turbine/Generator in the Solid Oxide Fuel Cell Hybrid Power Systems," CEPS Conference, Blacksburg, VA, 2005.

9. Macdonald, J.R.; "Impedance Spectroscopy," John Wiley \& Sons, Inc., New York, NY, 1987.

10. Xu M.; Wang C.; Qiu Y.; Lu B.; Lee F.C.; Kopasakis G.; "Controls and Simulation for Hybrid Solid Oxide Fuel Cell Power Systems," Applied Power Electronics Conference, Dallas, Texas, 2006 (pending).

11. Middlebrook, R.D.; "Topics in Multi-Loop Regulators and Current-Mode Programming," Proceedings of IEEE Power Electronics Specialist Conference, June, 1985.

12. Padulles J.; Ault G.W.; "An Integrated SOFC plant Dynamic Model for Power Systems Simulation," Journal of Power Sources, 86, 495-500, 2000.

13. Bejan A.; "Advanced Engineering Thermodynamics," John Wiley \& Sons, Canada, 1997.

14. Chick L.A.; Williford R.E.; Stevenson J.W.; Windisch Jr. C.F.; Simner S.P.; "Experimentally-Calibrated SpreadsheetBased SOFC Unit-Cell Performance Model," Proceedings of Fuel Cell Seminar, Palm Springs, CA, 2002.

15. Khaleel M.A.; Lin Z.; Singh P.; Surdoval W.; Collin D.; A Finite Element Analysis Modeling Tool for Solid Oxide Fuel Cel Development," Journal of Power Sources, 130, 136-148, 2004.

16. Reid R.C.; Prausnitz J.M.; Poling B.E.; "The Properties of Gases and Liquids," 4th Ed., McGraw-Hill, New York, 1987.

17. Suwanwarangkul R; et al.; "Performance comparison of Fick's, Dusty-Gas and Stefan-Maxwell Models to Predict the Concentration Overpotential of a SOFC Anode," Journal of Power Sources, 122, 9-18, 2003.

18. Qi Y.; Huang B.; Chuang K. T.; "Dynamic Modeling of Solid Oxide Fuel Cell: The Effect of Diffusion and Inherent Impedance," Journal of Power Sources, 150, 32-47, 2005.

19. Bieberle A.; "The Electrochemistry of Solid Oxyde Fuel Cell Anodes: Experiments, Modeling, and Simulations," Ph.D. Dissertation, Swiss Federal Institute of Technology, 2000.

20. Mitterdorfer A.; "Identification of the Oxygen Reduction at Cathodes of Solid Oxide Fuel Cells," Ph.D. Dissertation, Swiss Federal Institute of Technology, 1997. 
Public reporting burden for this collection of information is estimated to average 1 hour per response, including the time for reviewing instructions, searching existing data sources, gathering and maintaining the data needed, and completing and reviewing the collection of information. Send comments regarding this burden estimate or any other aspect of this collection of information, including suggestions for reducing this burden, to Washington Headquarters Services, Directorate for Information Operations and Reports, 1215 Jefferson Davis Highway, Suite 1204, Arlington, VA 22202-4302, and to the Office of Management and Budget, Paperwork Reduction Project (0704-0188), Washington, DC 20503.

\begin{tabular}{|l|l|l|}
\hline 1. AGENCY USE ONLY (Leave blank) & $\begin{array}{c}\text { 2. REPORT DATE } \\
\text { December } 2006\end{array}$ & $\begin{array}{r}\text { 3. REPORT TYPE AND DATES COVERED } \\
\text { Technical Memorandum }\end{array}$
\end{tabular}

4. TITLE AND SUBTITLE 5. FUNDING NUMBERS

A Theoretical Solid Oxide Fuel Cell Model for System Controls and Stability Design

6. $\operatorname{AUTHOR(S)}$

WBS 599489.02.07.03

George Kopasakis, Thomas Brinson, Sydni Credle, and Ming Xu

7. PERFORMING ORGANIZATION NAME(S) AND ADDRESS(ES)

National Aeronautics and Space Administration

John H. Glenn Research Center at Lewis Field

Cleveland, Ohio 44135-3191

8. PERFORMING ORGANIZATION REPORT NUMBER

E-15439

9. SPONSORING/MONITORING AGENCY NAME(S) AND ADDRESS(ES)

National Aeronautics and Space Administration

Washington, DC 20546-0001

10. SPONSORING/MONITORING AGENCY REPORT NUMBER

NASA TM-2006-214104

GT2006-91247

11. SUPPLEMENTARY NOTES

Prepared for the Turbo Expo 2006 sponsored by the American Society of Mechanical Engineers, Barcelona, Spain,

May 8-11, 2006. George Kopasakis, NASA Glenn Research Center; Thomas Brinson and Sydnia Credle, Florida

A \& M University, 1500 Wahnish Way, Tallahassee, Florida, 32307; Ming Xu, Virginia Polytechnic and State

University, 118 North Main Street, Blacksburg, Virginia 24061. Responsible person, George Kopasakis, organization code RIC, 216-433-5327.

12a. DISTRIBUTION/AVAILABILITY STATEMENT

12b. DISTRIBUTION CODE

Unclassified - Unlimited

Subject Categories: 07, 20, 25, and 34

Available electronically at http://gltrs.grc.nasa.gov

This publication is available from the NASA Center for AeroSpace Information, 301-621-0390.

13. ABSTRACT (Maximum 200 words)

As the aviation industry moves towards higher efficiency electrical power generation, all electric aircraft, or zero emissions and more quiet aircraft, fuel cells are sought as the technology that can deliver on these high expectations. The Hybrid Solid Oxide Fuel Cell system combines the fuel cell with a microturbine to obtain up to 70 percent cycle efficiency, and then distributes the electrical power to the loads via a power distribution system. The challenge is to understand the dynamics of this complex multi-discipline system, and design distributed controls that take the system through its operating conditions in a stable and safe manner while maintaining the system performance. This particular system is a power generation and distribution system and the fuel cell and microturbine model fidelity should be compatible with the dynamics of the power distribution system in order to allow proper stability and distributed controls design. A novel modeling approach is proposed for the fuel cell that will allow the fuel cell and the power system to be integrated and designed for stability, distributed controls, and other interface specifications. This investigation shows that for the fuel cell, the voltage characteristic should be modeled, but in addition, conservation equation dynamics, ion diffusion, charge transfer kinetics, and the electron flow inherent impedance should also be included.

14. SUBJECT TERMS

Fuel cells; Modeling; Dynamics; Systems stability and control

\begin{tabular}{|c|c|c|}
\hline $\begin{array}{c}\text { 17. SECURITY CLASSIFICATION } \\
\text { OF REPORT } \\
\text { Unclassified }\end{array}$ & $\begin{array}{c}\text { 18. SECURITY CLASSIFICATION } \\
\text { OF THIS PAGE } \\
\text { Unclassified }\end{array}$ & $\begin{array}{c}\text { 19. SECURITY CLASSIFICATION } \\
\text { OF ABSTRACT } \\
\text { Unclassified }\end{array}$ \\
\hline
\end{tabular}

NSN 7540-01-280-5500

Standard Form 298 (Rev. 2-89)

Prescribed by ANSI Std. Z39-18 298-102 

